\title{
Assessment and Clinical Significance of Micrometastases in Lymph Nodes of Head and Neck Cancer Patients Detected by E48 (Ly-6D) Quantitative Reverse Transcription-Polymerase Chain Reaction
}

\author{
Eline J. C. Nieuwenhuis, C. René Leemans, Alain Kummer, Fedor Denkers, \\ Gordon B. Snow, and Ruud H. Brakenhoff
}

Departments of Otolaryngology/Head-Neck Surgery and Pathology, Vrije Universiteit Medical Center, Amsterdam, The Netherlands

\begin{abstract}
SUMMARY: The presence of lymph node metastases is the major determinant for prognosis in head and neck squamous cell carcinoma (HNSCC). It is at present unknown whether the same holds true for the presence of histologically undetectable micrometastases. We analyzed 456 histologically tumor-negative lymph nodes of 23 HNSCC patients without (pN0) and 18 patients with one or two tumor-positive lymph nodes $(\mathrm{pN}+)$ in their neck dissection specimens at histopathologic examination. To detect the presence of disseminated tumor cells and micrometastases in these lymph nodes, we used real-time quantitative RT-PCR with E48 (Ly-6D) transcripts as a squamous cell-specific molecular marker. The results were compared with histopathologic examination and clinical outcome. E48 transcripts were detected in lymph nodes of 5 (22\%) of 23 patients in the pNO group, and in histologically negative lymph nodes of $10(56 \%)$ of 18 patients in the pN + group. In the pN0 group, the presence of E48-positive lymph nodes was significantly associated with a distinctly poor cause-specific survival as compared with those with E48-negative lymph nodes. Our results indicate that E48 real-time quantitative RT-PCR is a suitable method for the detection of micrometastases in lymph nodes of patients with HNSCC. Moreover, detection of micrometastases seems clinically relevant but should be confirmed in a large multicenter trial. (Lab Invest 2003, 83:1233-1240).
\end{abstract}

$H$ ead and neck squamous cell carcinoma (HNSCC) accounts for $5 \%$ of all newly diagnosed cancers in the Western world (Muir and Weiland, 1995). Dissemination to lymph nodes in the neck is one of the most important prognosticators for HNSCC. Only $7 \%$ of patients without lymph node metastases develop distant metastases, whereas this occurs in $50 \%$ of patients with more than three tumor-positive lymph nodes (Leemans et al, 1993). Moreover, when tumor is diagnosed in the regional lymph nodes, the neck should be treated. The clinical management is further determined by the number of tumor-containing lymph nodes, the involved level(s) in the neck, and the presence of extranodal spread. Therefore, accurate assessment of the regional lymph nodes for metastases is of crucial importance. However, classical diagnostic modalities, such as radiologic and histopathologic examination are of limited sensitivity to detect small numbers of tumor cells.

DOI: 10.1097/01.LAB.0000083532.46536.56

Received February 28, 2003.

This work was supported by the Dutch Cancer Society (Grant VU 99-1967).

Address reprint requests to: Dr. R. H. Brakenhoff, Department of Otolaryngology/Head and Neck Surgery, Vrije Universiteit Medical Center, P.O. Box 7057, 1007 MB Amsterdam, The Netherlands. E-mail: rh.brakenhoff@ vumc.nl
Recently, molecular techniques have been applied in a number of studies to detect the presence of micrometastases that are missed at routine histologic examination for the early diagnosis of cancer (Brennan et al, 1995; Gath and Brakenhoff, 1999; Pantel, 1996; Pantel et al, 1999; Van Houten et al, 2000). In other types of cancer, including breast cancer, esophageal cancer, and melanoma, the molecular detection of micrometastases in lymph nodes of patients with histologically tumor-negative lymph nodes has been shown to be prognostically important (Bostick et al, 1999; Cote et al, 1999; McGuckin et al, 1996). It has been demonstrated for example, that carcinoembryonic antigen as a marker for tumor cells was successfully applied in patients with Stage II (histologically negative lymph nodes) colorectal cancer. The presence of carcinoembryonic antigen transcripts in lymph nodes significantly correlated with a poor prognosis (Liefers et al, 1998). These studies emphasize the importance of molecular assessment of micrometastases in histopathologically tumor-negative lymph nodes, which may improve tumor staging.

At our laboratory, we are focusing on the exploitation of SCC-specific antigen E48 (Ly-6D) as a potential marker for the detection of HNSCC. This antigen is specifically expressed in squamous cells of normal, malignant, and transitional epithelia (Quak et al, 1990). 
In a previous study, we demonstrated that E48 transcripts can serve as a highly sensitive and specific molecular marker for squamous cell detection in blood and bone marrow (Brakenhoff et al, 1999). Subsequently, we described a quantitative real-time RT-PCR assay to assess the presence of squamous cells in lymph nodes aspirates. In this study 235 lymph node aspirate residues of 64 HNSCC patients staged with ultrasound-guided fine needle aspiration cytology were examined for the presence of E48 mRNA and compared with routine cytologic examination. The gene encoding porphobilinogen deaminase (PBGD), a consistently expressed housekeeping gene, was used to determine the quality and quantity of isolated RNA. Our data demonstrated a clear benefit of molecular diagnosis on the sensitivity and frequency of diagnosis. In the 191 aspirates that were tumor-negative or not evaluable at cytology, 8 samples from 6 patients were positive for E48. These results were confirmed by histologic examination or clinical outcome in three of six patients (Nieuwenhuis et al, 2003).

Minimal data exist on the presence and clinical significance of minimal residual disease in lymph nodes of HNSCC patients. In a previous study, we analyzed 76 neck dissection specimens from 64 HNSCC patients (Van den Brekel et al, 1996). The percentage of additional micrometastases detected in tumor-negative neck dissection specimens was $3 \%$ (2/62) when one additional section was analyzed by routine histopathologic examination, and 10\% (1/10) when using immunohistochemical staining with anticytokeratin antibodies. In another study, using p53 point mutations as marker, the presence of tumor cell DNA was detected in $21 \%$ of histopathologically tumor-negative lymph nodes (Brennan et al, 1995). In none of these studies, however, could the clinical significance be determined. Moreover, the sensitivity of these techniques is still not optimal because only limited amounts of tissues can be analyzed. Using quantitative E48 RT-PCR, however, we can specifically detect a single squamous cell in a background of $10^{6}$ peripheral blood mononuclear cells (Nieuwenhuis et al, 2003).

The aim of the present study was to investigate the presence and prognostic relevance of micrometastases in lymph nodes of HNSCC patients using a quantitative E48 RT-PCR assay.

\section{Results}

\section{E48 RT-PCR of Lymph Nodes}

The 10-fold serial dilution of UM-SCC-22A RNA for E48 amplification, ranging from $500,000 \mathrm{pg}$ to $5 \mathrm{pg}$, is shown in Figure 1. The standard curve of these dilutions is depicted in Figure 2. Based on these experiments, the dynamic range of quantitation was 5 -log with a correlation coefficient $>0.99$. From previous dilution experiments using the cell line UM-SCC-22A, the detection limit of this E48 RTPCR assay was a single tumor cell in a background of $10^{6}$ peripheral blood mononuclear cells (Nieu-

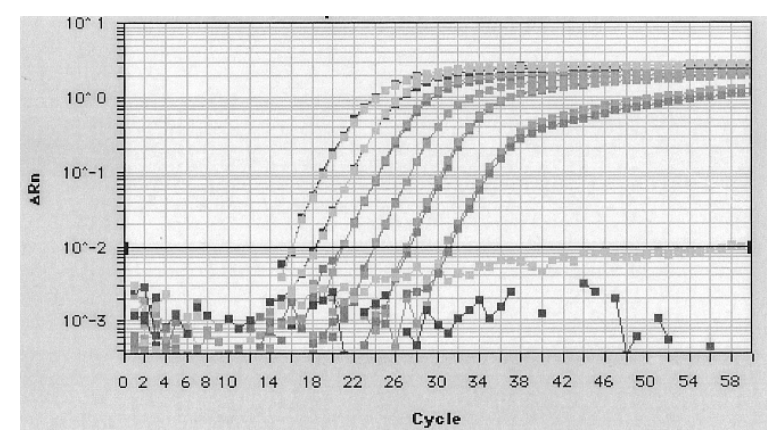

Figure 1.

Serial dilution of UM-SCC-22A RNA ranging from 500,000 to $5 \mathrm{pg}$ analyzed by E48 quantitative RT-PCR. PCR cycles are shown on the $x$ axis. $\triangle R n$ on the $y$ axis indicates the fluorescent signal of the cleaved probe. A $\Delta R n$ of 0.01 was chosen to define the threshold cycle $\left(\mathrm{C}_{\mathrm{T}}\right)$.

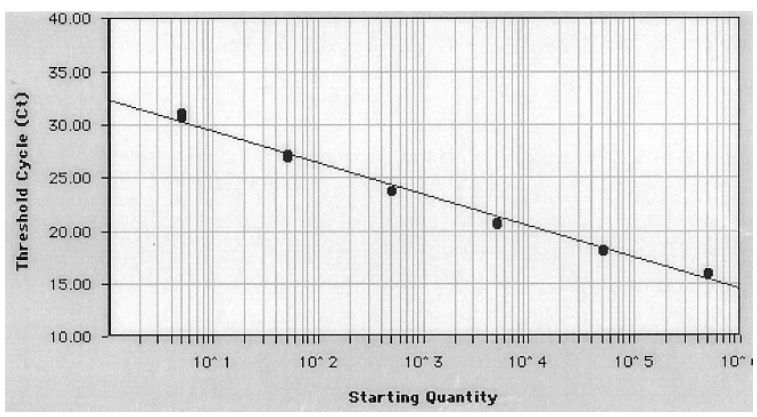

Figure 2

Standard curve of E48 quantitative RT-PCR in a serial dilution ranging from 500,000 to $5 \mathrm{pg}$ of UM-SCC-22A RNA. The $\mathrm{C}_{\mathrm{T}}$ value on the $y$ axis was plotted to the log amount (in pg) of UM-SCC-22A RNA at the $x$ axis. The correlation coefficient was 0.991 . The amount of $\mathrm{E} 48$ (and gene encoding porphobilinogen deaminase) mRNA of each clinical sample was calculated relative to this standard curve of UM-SCC-22A RNA.

wenhuis et al, 2003). The cut-off level to call a sample positive or negative was set on $2 \mathrm{pg}$ relative to UM-SCC-22A. This was the lowest level that duplicates were always within $20 \%$ variation. Setting the limits higher caused a reduction in sensitivity (Nieuwenhuis et al, 2003). We defined a lymph node sample as representative when a minimum number of 1,000 peripheral blood mononuclear cells was present, which corresponds to a PBGD RNA value of approximately $100 \mathrm{pg}$ UM-SCC-22A equivalents (Nieuwenhuis et al, 2003).

In total 15 lymph nodes of 3 noncancer controls were collected and tested. A positive signal was not detected in any of these lymph nodes. A total of 456 lymph nodes from 41 patients (range 7-20 per patient, median 10) were selected for E48 RT-PCR. Only 1 of 456 lymph nodes did not yield sufficient RNA as assessed by the control PCR from PBGD. All 22 histopathologic tumor-positive lymph nodes showed E48 transcript-positive signals in duplicate. Of the remaining 433 lymph nodes that were tumor-negative at routine histopathologic examination, 24 (5.5\%) revealed E48-positive signal. Overall, 15 (37\%) of 41 patients showed E48 transcript-positive signals (in duplicate) in at least one lymph node. 


\section{Molecular N-Staging in Relation to Histopathology}

Tables 1 and 2 presents the data on patient characteristics, E48 RT-PCR results of the analyzed lymph nodes, and the clinical outcome of the pNO group and the $\mathrm{pN}+$ group, respectively. In the pNO group $5(22 \%)$ of 23 patients showed E48 signal in one (4 patients) or two (1 patient) lymph nodes, whereas in the $\mathrm{pN}+$ group 10 (56\%) of 18 patients had E48 signal in one (7 patients) or more (3 patients) histologically tumornegative lymph nodes. Overall, 15 (37\%) of 41 patients had at least one E48-positive lymph node, and 7 of 15 were upstaged with regard to $\mathrm{N}$-stage (N0 to $\mathrm{N} 1$ or $\mathrm{N} 1 / 2 \mathrm{a}$ to N2b). T-stage and site did not differ significantly between the patients with and without E48positive lymph nodes as determined by Fisher's exact test. The detection of the micrometastases would have influenced postoperative treatment in only one patient in this study (Table 2, Case 8). The other patients had already received postoperative radiotherapy based on the clinical T-stage (T3 or T4) or the histopathologic status of the neck (multiple tumorpositive lymph nodes and/or extranodal spread).

From Table 2 it can be seen that in 6 of 10 patients, the E48-positive lymph nodes were found in levels similar to the metastases found at routine histopathologic examination. However, in 4 of 10 cases (Cases 2, 8,9 , and 16), additional lymph node metastases were found in levels not adjacent to the histopathologically tumor-involved levels. Micrometastases could not be identified in any of the lymph nodes after histopathologic review of the paraffin sections by the pathologist.

\section{Molecular N-Staging and Clinical Outcome}

When all patients were considered ( $\mathrm{pNO}$ and $\mathrm{pN}+$ ), molecular $\mathrm{N}$-staging was not related to a poor causespecific survival. However, when the pNO patients were considered separately, there was a significant correlation between molecular $\mathrm{N}$-staging and causespecific survival $(p=0.002$, data not shown). It should

Table 1. Tumor Characteristics, Molecular Analyses, and Clinical Outcome of 23 pNO Patients (pNO Group)

\begin{tabular}{|c|c|c|c|c|c|c|c|c|}
\hline \multirow[b]{2}{*}{ Case } & \multirow[b]{2}{*}{ Tumor site } & \multirow[b]{2}{*}{ T-stage } & \multirow[b]{2}{*}{ RT } & \multicolumn{3}{|c|}{ Lymph nodes } & \multirow[b]{2}{*}{ Patient status } & \multirow{2}{*}{$\begin{array}{l}\text { Follow-up } \\
\text { (mo) }\end{array}$} \\
\hline & & & & No. analyzed & No. E48 positive & Level(s) involved & & \\
\hline 1 & Tonsil & 2 & $\mathrm{~N}$ & 10 & 0 & - & Alive & 48.5 \\
\hline 2 & M Tongue & 2 & Y & 7 & 0 & - & Alive & 50 \\
\hline 3 & Tonsil & 3 & Y & 12 & 2 & 1 & DOD & 28 \\
\hline 4 & Larynx & 3 & Y & 10 & 0 & - & Alive & 46.5 \\
\hline 5 & $\begin{array}{l}\text { Inf Alv } \\
\text { Process }\end{array}$ & 4 & N & 10 & 0 & - & Alive & 48 \\
\hline 6 & $\begin{array}{l}\text { Inf Alv } \\
\text { Process }\end{array}$ & 4 & $\mathrm{~N}$ & 12 & 0 & - & Alive & 43 \\
\hline 7 & FOM & 1 & $\mathrm{~N}$ & 10 & 0 & - & Alive & 41.5 \\
\hline 8 & $\begin{array}{l}\text { Inf Alv } \\
\text { Process }\end{array}$ & 3 & Y & 10 & 0 & - & Alive & 44 \\
\hline 9 & Tonsil & 3 & Y & 10 & 0 & - & Alive & 46 \\
\hline 10 & Tonsil & 3 & Y & 14 & 1 & III & DOD & 14 \\
\hline 11 & $\begin{array}{l}\text { Inf Alv } \\
\text { Process }\end{array}$ & 2 & N & 10 & 0 & - & $\mathrm{DOC}$ & 19 \\
\hline 12 & Oropharynx & 2 & $\mathrm{~N}$ & 10 & 0 & - & Alive & 41 \\
\hline 13 & $\begin{array}{l}\text { Inf Alv } \\
\text { Process }\end{array}$ & 4 & Y & 10 & 0 & & Alive & 39 \\
\hline 14 & M Tongue & 2 & N & 10 & 0 & - & Alive & 34 \\
\hline 15 & $\begin{array}{l}\text { Inf Alv } \\
\text { Process }\end{array}$ & 4 & Y & 8 & 0 & - & Alive & 9 \\
\hline 16 & Tonsil & 3 & Y & 10 & 0 & - & $\mathrm{DOC}$ & 21 \\
\hline 17 & FOM & 4 & Y & 15 & 0 & - & Alive & 32.5 \\
\hline 18 & B Tongue & 2 & Y & 10 & 0 & - & Alive & 31 \\
\hline 19 & M Tongue & 3 & $\mathrm{Y}$ & 10 & 1 & III & Alive & 24 \\
\hline 20 & FOM & 2 & $\mathrm{~N}$ & 14 & 1 & II & Alive & 23 \\
\hline 21 & $\begin{array}{l}\text { Inf Alv } \\
\text { Process }\end{array}$ & 4 & Y & 9 & 0 & - & Alive & 19 \\
\hline 22 & $\begin{array}{l}\text { Inf Alv } \\
\text { Process }\end{array}$ & 4 & Y & 10 & 1 & III & Alive & 20 \\
\hline 23 & $\begin{array}{l}\text { Buccal } \\
\text { Mucosa }\end{array}$ & 4 & Y & 10 & 0 & - & Alive & 20 \\
\hline
\end{tabular}

M Tongue, mobile tongue; B Tongue, base of tongue; FOM, floor of mouth; Inf Alv Process, inferior alveolar process; RT, postoperative radiotherapy; Y, yes; N, no; DOD, dead of disease; DOC, dead of other cause. 
Table 2. Tumor Characteristics, Molecular Analyses and Clinical Outcome of 18 Patients with One (Cases 1-11) or Two (Cases 12-18) of Lymph Node Metastases Found at Routine Histopathologic Examination (pN+ Group)

\begin{tabular}{|c|c|c|c|c|c|c|c|c|c|}
\hline \multirow[b]{2}{*}{ Case } & \multirow[b]{2}{*}{ Tumor site } & \multirow[b]{2}{*}{ pTN-stage } & \multirow[b]{2}{*}{ RT } & \multicolumn{4}{|c|}{ Lymph nodes } & \multirow[b]{2}{*}{ Patient status } & \multirow[b]{2}{*}{$\begin{array}{l}\text { Follow-up } \\
\text { (mo) }\end{array}$} \\
\hline & & & & $\begin{array}{c}\text { Pos at PA } \\
\text { level }\end{array}$ & $\begin{array}{l}\text { No. analysed } \\
\text { RT-PCR }\end{array}$ & $\begin{array}{c}\text { No. } \\
\text { E48- } \\
\text { positive }\end{array}$ & $\begin{array}{l}\text { Level(s) } \\
\text { involved }\end{array}$ & & \\
\hline 1 & $\begin{array}{l}\text { Piriform } \\
\text { Sinus }\end{array}$ & T2N1 & $Y$ & II & 11 & 0 & - & Alive & 53.5 \\
\hline 2 & FOM & T3N1 & $Y$ & III & 10 & 3 & $\begin{array}{l}\text { II } \\
\text { V }\end{array}$ & DOD & 35.5 \\
\hline 3 & Tonsil & T3N1 & $\mathrm{Y}$ & $\|$ & 10 & 0 & - & Alive & 53 \\
\hline 4 & Tonsil & T3N1 & $\mathrm{Y}$ & II & 11 & 0 & - & DOD & 23 \\
\hline 5 & B Tongue & T2N1 & Y & II & 12 & 0 & - & Alive & 50.5 \\
\hline 6 & Tonsil & T3N1 & $Y$ & II & 13 & 1 & II & Alive & 48 \\
\hline 7 & Tonsil & T3N1 & Y & $\|$ & 12 & 2 & $\|$ & Alive & 49 \\
\hline 8 & M Tongue & T2N1 & $\mathrm{N}$ & III & 13 & 1 & I & Alive & 47 \\
\hline 9 & Oropharynx & $\operatorname{Rec}^{a}$ & $\mathrm{~N}$ & III & 10 & 2 & II & Alive & 35.5 \\
\hline 10 & Tonsil & T2N1 & Y & II & 10 & 6 & $\begin{array}{l}\text { I, II } \\
\text { III, IV }\end{array}$ & Alive & 30.5 \\
\hline 11 & FOM & T2N1 & Y & II & 11 & 0 & - & Alive & 31.5 \\
\hline 12 & FOM & T3N2b & $Y$ & $|/| \mid$ & 20 & 0 & - & DOC & 17 \\
\hline 13 & Oropharynx & T3N2b & $\mathrm{Y}$ & II & 9 & 1 & II & DOD & 8 \\
\hline 14 & $\begin{array}{l}\text { Piriform } \\
\text { Sinus }\end{array}$ & T4N2b & $Y$ & II/IV & 14 & 1 & IV & DOC & 9 \\
\hline 15 & FOM & T2N2b & Y & $\begin{array}{l}\text { I L } \\
\text { I R }\end{array}$ & 16 & 0 & - & Alive & 48 \\
\hline 16 & Oropharynx & $\mathrm{T} 2 \mathrm{~N} 2 \mathrm{~b}$ & Y & $\|$ & 12 & 1 & IV & Alive & 46 \\
\hline 17 & Oropharynx & T2N2b & $\mathrm{Y}$ & III/IV & 10 & 1 & IV & DOD & 22 \\
\hline 18 & M Tongue & $\mathrm{T} 2 \mathrm{~N} 2 \mathrm{~b}$ & $\mathrm{Y}$ & III & 11 & 0 & - & DOD & 19 \\
\hline
\end{tabular}

The pathologic TN stage is indicated in column 3 and the levels of the tumor-positive lymph nodes found at routine histopathologic examination in column 5 . The number of additional metastases assessed by E48 RT-PCR is indicated in column 7, whereas the next column specifies the levels of these E48-positive lymph nodes. Rec, recurrence.

${ }^{a}$ This patient developed a local recurrence after primary radiotherapy.

be noted, however, that the number of patients and events is small.

\section{Discussion}

The presence or absence of lymph node metastases is the strongest prognosticator in HNSCC. Not only the presence of metastases but also the number of nodal metastases, the level(s) in the neck, the size of the nodes, and the presence of extranodal spread are important prognostic factors (Jones et al, 1994; Leemans et al, 1990; Shah, 1990; Snow et al, 1982; Stell et al, 1983). Although preoperative node assessment using imaging techniques has improved over time, histologic assessment is the most reliable diagnostic modality, particularly for detecting smaller metastases, and therefore the gold standard. However, patients can harbor occult metastases that are missed by histologic examination as well. These remain undetected mainly because of sampling error because only single paraffin sections are analyzed routinely.

Immunohistochemical staining has been shown to improve the detection of micrometastases. For example, Izbicki et al (1997) (Table 3) demonstrated the presence of micrometastases in patients with esophageal carcinoma by immunostaining with Ber-EP4 antibody in $17 \%$ of lymph nodes that were tumor free on the basis of routine histopathologic analysis, which correlated with a significant worse prognosis (Izbicki et al, 1997). However, their statistical analyses involved a comparison between patients with lymph node metastases versus patients without lymph node metastases with Ber-EP4-positive cells, regardless of histologically identifiable metastases. When patients with histologically overt lymph node metastases were excluded from the analysis, a comparison of patients with versus patients without occult lymph node metastases yielded no significant effect on overall survival. Recently, the histologically pNO patient group was enlarged and it was shown that the presence of Ber-EP4-positive cells in lymph nodes was significantly associated with a reduced relapse-free survival (Hosch et al, 2000). In another study, Glickman et al (1999) detected histologically occult lymph node metastases in $20(26 \%)$ of 78 esophageal carcinoma patients using immunostaining with a pan-cytokeratin antibody, but these findings were not associated with patient outcome. Kano et al (2000) analyzed lymph nodes of three patients without histologically involved lymph nodes and lymph nodes of 11 patients with nodal involvement and found upstaging of the lymph 
Table 3. Micrometastases Detection in pNO and pN+ Patients in Esophageal Cancer and HNSCC

\begin{tabular}{|c|c|c|c|c|c|}
\hline Source year & No. of patients & Upstaged patients $^{a}$ & Marker & Method & $\begin{array}{l}\text { No. of molecular } \\
\text { or IHC-positive } \\
\text { LN per patient }\end{array}$ \\
\hline \multicolumn{6}{|l|}{ Esophageal carcinoma } \\
\hline $\begin{array}{l}\text { Glickman et al, } \\
1999\end{array}$ & 78 pNO & $26 \%$ & AE1/AE3 & IHC & $1-4$ \\
\hline Hosch et al, 2000 & $\begin{array}{l}54 \mathrm{pN} 0 \\
72 \mathrm{pN} 1\end{array}$ & $\begin{array}{l}56 \% \\
82 \%\end{array}$ & Ber-EP4 & IHC & \\
\hline Kano et al, 2000 & $\begin{array}{r}3 \text { pN0 } \\
11 \text { pN1 }\end{array}$ & $\begin{array}{r}100 \% \\
91 \%\end{array}$ & SCC antigen & $\mathrm{IHC}$ & $\begin{array}{l}1-5 \\
1-8\end{array}$ \\
\hline \multicolumn{6}{|l|}{ HNSCC } \\
\hline $\begin{array}{l}\text { McDonald et al, } \\
1998\end{array}$ & 16 pNo & $63 \%$ & CK5 & RT-PCR & $1-8$ \\
\hline & $8 \mathrm{pN}+{ }^{b}$ & $75 \%$ & & & $1-8$ \\
\hline $\begin{array}{l}\text { Cortesina et al, } \\
2000\end{array}$ & 5 pNO & $100 \%$ & MET & Quantitative RT-PCR & $2-5$ \\
\hline This study & $\begin{array}{l}15 \mathrm{pN} 1-2 \mathrm{c} \\
23 \mathrm{pNO} \\
18 \mathrm{pN}+\end{array}$ & $\begin{array}{l}33 \% \\
22 \% \\
56 \%\end{array}$ & E48 & Quantitative RT-PCR & $\begin{array}{l}1-2 \\
1-6\end{array}$ \\
\hline
\end{tabular}

a \% of patients with molecular or immunostaining tumor-positive but histopathologically tumor-negative lymph nodes.

${ }^{b} \mathrm{~N}+:$ 1-3 histopathologic tumor-positive lymph nodes.

node status in 13 patients. These studies demonstrated that stepwise sectioning and immunostaining decrease the number of unidentified metastases. However, the enormous workload and costs are major disadvantages for immunostaining of multiple sections and will always hamper implementation in routine practice. In contrast, RT-PCR is less laborious and might overcome, at least in part, the problem of sampling error, because the entire lymph node can be assessed by RT-PCR. This technique was used by McDonald et al (1998), who examined 196 lymph nodes of 24 HNSCC patients for the presence of cytokeratin 5 mRNA. They demonstrated the presence of cytokeratin 5 transcripts in $40 \%$ of the lymph nodes that were histologically negative for tumor. However, the prognostic value of this molecular $\mathrm{N}$-staging was not discussed.

Real-time quantitative RT-PCR offers several advantages compared with conventional RT-PCR. First, the technique permits precise quantitation of minute amounts of mRNA transcripts over a 5-log range. Second, PCR is performed in a closed tube system and does not require post-PCR manipulations, thereby preventing possible contamination. Third, because of the lack of post-PCR processing time, sample throughput is increased. Cortesina et al (2000) investigated the expression of the MET oncogene in 20 HNSCC patients using quantitative RT-PCR. The presence of MET mRNA was demonstrated in $40 \%$ of the histologically negative lymph nodes. Again, the relationship between the presence of MET expression in lymph nodes and prognosis was not evaluated.

In this study we evaluated the prevalence and prognostic significance of histologically occult lymph node metastases in HNSCC patients using the SCCassociated E48 antigen (Ly-6D), expressed on normal, malignant, and transitional epithelia, as a molecular marker. In a previous study, we demonstrated that E48 transcripts can serve as a highly sensitive and specific molecular marker for squamous cell detection in blood and bone marrow (Brakenhoff et al, 1999). Our results show that $22 \%$ of pN0 patients and $56 \%$ of $\mathrm{pN}+$ patients had $\mathrm{E} 48$ transcript-positive signals in at least one of the resected histologically tumornegative lymph nodes. Survival analysis revealed that patients in the pNO group with one or more molecularpositive lymph nodes had a significantly worse causespecific survival compared with patients with molecular-negative lymph nodes, although this conclusion is based on only small patient numbers and a small number of events.

In conclusion, real-time E48 quantitative RT-PCR is an accurate technique for assessment of micrometastases in lymph nodes. Our study shows that the frequency of lymph node metastasis is underestimated. Moreover, our results demonstrate that micrometastases in HNSCC patients without histopathologic positive lymph nodes contribute to a poor prognosis. It has been shown previously that only $7 \%$ of NO patients develop distant metastases (Leemans et al, 1993). When sensitive molecular assays such as E48 quantitative RT-PCR are exploited for N-staging, the percentage could even be much lower, suggesting that hematogenic dissemination follows initial lymphatic spread in HNSCC. Large multicenter studies will be necessary to confirm these preliminary results in a large patient group. Although in this study only frozen material was used, which provides RNA of good quality, recent improvements in quantitative RTPCR analyses on RNA isolated from archival, formalinfixed, and paraffin-embedded material will help to initiate studies in larger cohorts (Specht et al, 2001). A direct application of E48 quantitative RT-PCR could be the combination with sentinel node identification 
and biopsy. The putative additional value of this approach should be further investigated.

\section{Patients and Methods}

\section{Subjects}

Between August 1997 and July 2000, 69 patients with histopathologically proven HNSCC entered the study. The protocol was approved by the Institutional Review Board, and informed consent was obtained from all patients. All patients were treated by radical primary tumor excision and uni- or bilateral neck dissection, depending on the extension of the tumor toward the midline. A univariate analysis of this patient group showed that the 41 patients with zero, one, or two histologically tumor-positive lymph nodes in their neck dissection specimen had a relatively good prognosis compared with the 28 patients with more than two tumor-involved lymph nodes $(p<0.001$, data not shown). Therefore, we proceeded with these 41 patients for further molecular detection of micrometastases. The cohort consisted of 30 men and 11 women, with an age ranging from 40 to 77 (median, 57) years. In the neck dissection specimens, the different levels were identified according to the classification system of the American Academy of Otolaryngology/Head and Neck Surgery. The two largest lymph nodes were removed from each level. One half of the two largest lymph nodes and the remaining lymph nodes in the various levels were fixed in formalin and embedded in paraffin for routine histopathologic examination. The other half of the two largest lymph nodes was snapfrozen in liquid nitrogen and stored at $-80^{\circ} \mathrm{C}$ until RNA isolation. Nodes larger than $1 \mathrm{~cm}$ in diameter were not halved but were sliced and alternately embedded in paraffin or snap-frozen. Histopathologic examination showed no tumor-positive lymph nodes in 23 patients (pNO group), one tumor-positive lymph node in 11 patients ( $\mathrm{pN}+$ group), and two tumorcontaining lymph nodes in 7 patients ( $\mathrm{pN}+$ group). Follow-up visits were performed every 6 weeks during the first year after treatment to check for recurrent disease; thereafter the interval gradually increased. Fifteen lymph nodes from the neck were obtained from three noncancer patients and served as negative control. In total 22 histopathologic tumor-positive lymph nodes from the $\mathrm{pN}+$ patient group were used as positive control.

\section{RNA Isolation}

The lymph nodes were homogenized using a micropestle in $1 \mathrm{ml}$ of RNAzol B (Campro Scientific bv., Veenendaal, Holland). After addition of $100 \mu \mathrm{l}$ of chloroform, the solution was mixed vigorously for 15 seconds and put on ice for 5 minutes. After centrifugation at $12,000 \times g$ for 15 minutes at $4^{\circ} \mathrm{C}$, the aqueous phase was transferred to another microcentrifuge vial, an equal volume of isopropanol was added for precipitation, and the solution was incubated on ice for 15 minutes. Glycogen $(20 \mu \mathrm{g})$ was used as carrier for RNA precipitation. The RNA precipitate was collected by centrifugation at $12,000 \times g$ for 30 minutes at $4^{\circ} \mathrm{C}$. The pellet was washed in $70 \%$ ethanol, and centrifuged at $12,000 \times g$ for 5 minutes at $4^{\circ} \mathrm{C}$. The pellet was dissolved in 25 to $100 \mu$ l of RNAse-free water and when necessary incubated at $65^{\circ} \mathrm{C}$ for 15 minutes. The amount of RNA was calculated from the absorbance at $260 \mathrm{~nm}$. Subsequently, concentrations of $100 \mathrm{ng} / \mu \mathrm{l}$ total RNA were prepared.

\section{cDNA Synthesis and Real-Time PCR Amplification}

The sequences of the intron-spanning amplification primers and probe for E48 were as follows: AGATGAGGACAGCATTGCTGC, GCAGACCACAGAATGCTTGC, and FAM-TTACCCTGCGCTGCCACGTGTG-TAMRA, respectively. These primers were selected with $A B I /$ Prism Primer Express (Applied Biosystems, Warrington, United Kingdom). For internal calibration of the samples, we used mRNA transcribed from the gene encoding PBGD, a consistently expressed housekeeping gene. The sequences of the intron-spanning amplification primers and probe for PBGD were as follows: GGCAATGCGGCTGCAA, GGGTACCCACGCGAATCAC, and FAM-CATCTITGGGCTGTITCTTCCGCC-TAMRA. In total $5 \mu \mathrm{l}$ of RNA (500 ng) was heated to $65^{\circ} \mathrm{C}$ for 5 minutes and cooled directly on ice. Subsequently, $15 \mu \mathrm{l}$ of RT mixture was added. The RT mixture consisted of 2 $\mu$ l of $10 \times \mathrm{RT}$ buffer $(600 \mathrm{~mm} \mathrm{KCl,} 30 \mathrm{~mm} \mathrm{MgCl}, 500 \mathrm{~mm}$ Tris), $2 \mu$ l of $10 \mathrm{~mm}$ DTT, $2 \mu \mathrm{l}$ of $10 \mathrm{~mm}$ dNTPs $(2.5 \mathrm{~mm}$ each deoxynucleotide triphosphate), $1 \mu$ l of reverse primer E48+95 $\alpha$ s or HuPBGD.R $(25 \mathrm{pmol} / \mu \mathrm{l}), 7.85 \mu \mathrm{l}$ of sterile $\mathrm{H}_{2} \mathrm{O}, 0.05 \mu \mathrm{l}$ of RNasin $(40 \mathrm{U} / \mu \mathrm{l})$, and $0.1 \mu \mathrm{l}$ of AMV-RT $(10 \mathrm{U} / \mu \mathrm{l})$. The reaction mixture was incubated for 2 hours at $42^{\circ} \mathrm{C}$. All reactions were performed in duplicate.

After completion of the RT reaction, $5 \mu$ of cDNA was used for PCR amplification in 60 cycles in a $50-\mu$ l reaction mixture, containing $5 \mu l 10 \times$ TaqMan buffer $A$ (Applied Biosystems), $10 \mu \mathrm{l}$ of $25 \mathrm{~mm} \mathrm{MgCl}, 0.5 \mu \mathrm{l}$ of $100 \mathrm{~mm}$ dNTP, $0.6 \mu \mathrm{l}$ of sense and antisense primers of E48 or PBGD (25 pmol $/ \mu$ l each), $1.5 \mu \mathrm{l}$ of fluorescent probe ( $5 \mathrm{pmol} / \mu \mathrm{l}), 26.55 \mu \mathrm{l}$ of sterile $\mathrm{H}_{2} \mathrm{O}$ (Baxter), and $0.25 \mu \mathrm{l}$ AmpliTaq Gold DNA-polymerase (5 U/ $\mu$, Applied Biosystems). Real-time PCR was performed on the ABI/Prism 7700 Sequence Detector System (Applied Biosystems), using a pre-PCR step of 10 minutes at $95^{\circ} \mathrm{C}$, followed by 60 cycles of 15 seconds at $95^{\circ} \mathrm{C}$ and 60 seconds at $60^{\circ} \mathrm{C}$. In each experiment a serial dilution of UM-SCC-22A RNA ranging from 500,000 to $50 \mathrm{pg}$ was run in parallel as a calibration curve for both E48 and PBGD. The original amount of E48 and PBGD mRNA in each sample was calculated from the standard curve relative to the human HNSCC cell line UM-SCC-22A. The range of duplicates was usually within $20 \%$ variation, and the mean of duplicates was used for further calculations.

\section{Quality Assurance and Controls}

The primers, probes and buffers were prepared in a laboratory that is isolated from PCR product analysis and sample preparation. RNA isolation, cDNA synthe- 
sis, and preparation of $\mathrm{PCR}$ reactions were performed in a pre-PCR laboratory. To prevent amplimer carryover contamination, all materials and reagents were transported in a one-way direction from the pre-PCR laboratories to the post-PCR laboratory. Sample-tosample carryover contamination was further avoided using different pipet sets and filter tips (Greiner BioOne, Kremsmünster, Austria). Preparations without RNA template were used as negative RT-PCR control.

\section{Statistical Analysis}

Cause-specific and disease-free survival were determined by the Kaplan-Meier analysis, and differences between the curves were calculated by the log-rank test. Differences in frequency distributions were analyzed by Fisher's exact test. $P$ values $<0.05$ were considered as significant.

\section{Acknowledgement}

We thank Prof. I. van der Waal (Department of Oral and maxillofacial surgery/Oral Pathology, Vrije Universiteit Medical Center, Amsterdam) for histologic review of all paraffin sections.

\section{References}

Bostick PJ, Morton DL, Turner RR, Huynh KT, Wang HJ, Elashoff R, Essner R, and Hoon DS (1999). Prognostic significance of occult metastases detected by sentinel lymphadenectomy and reverse transcriptase-polymerase chain reaction in early-stage melanoma patients. J Clin Oncol 17:3238-3244.

Brakenhoff RH, Stroomer JG, Ten Brink CBM, De Bree R, Weima SM, Snow GB, and van Dongen GAMS (1999). Sensitive detection of squamous cells in bone marrow and blood of head and neck cancer patients by E48 reverse transcriptase-polymerase chain reaction. Clin Cancer Res 5:725-732.

Brennan JA, Mao L, Hruban RH, Boyle JO, Eby YJ, Koch WM, Goodman SN, and Sidransky D (1995). Molecular assessment of histopathological staging in squamous-cell carcinoma of the head and neck. N Engl J Med 332:429-435.

Cortesina G, Martone T, Galeazzi E, Olivero M, De Stefani A, Bussi M, Valente G, Comoglio PM, and Di Renzo MF (2000). Staging of head and neck squamous cell carcinoma using the MET oncogene product as marker of tumor cells in lymph node metastases. Int J Cancer 89:286-292.

Cote RJ, Peterson HF, Chaiwun B, Gelber RD, Goldhirsch A, Castiglione-Gertsch M, Gusterson B, and Neville AM (1999). Role of immunohistochemical detection of lymph-node metastases in management of breast cancer. International Breast Cancer Study Group. Lancet 354:896-900.

Gath HJ and Brakenhoff RH (1999). Minimal residual disease in head and neck cancer. Cancer Metastasis Rev 18:109126.

Glickman JN, Torres C, Wang HH, Turner JR, Shahsafaei A, Richards WG, Sugarbaker DJ, and Odze RD (1999). The prognostic significance of lymph node micrometastasis in patients with esophageal carcinoma. Cancer 85:769-778.

Hosch S, Kraus J, Scheunemann P, Izbicky JR, Schneider C, Schumacher U, Witter K, Speicher MR, and Pantel K (2000).
Malignant potential and cytogenetic characteristics of occult disseminated tumor cells in esophageal cancer. Cancer Res 60:6836-6840.

Izbicki JR, Hosch SB, Pichlmeier U, Rehders A, Busch C, Niendorf A, Passlick B, Broelsch CE, and Pantel K (1997). Prognostic value of immunohistochemically identifiable tumor cells in lymph nodes of patients with completely resected esophageal cancer. N Engl J Med 337:1188-1194.

Jones AS, Roland NJ, Field JK, and Phillips DE (1994). The level of cervical lymph node metastases: Their prognostic relevance and relationship with head and neck squamous carcinoma primary sites. Clin Otolaryngol 19:63-69.

Kano M, Shimada Y, Kaganoi J, Sakurai T, Li Z, Sato F, Watanabe G, and Imamura M (2000). Detection of lymph node metastasis of oesophageal cancer by RT-nested PCR for SCC antigen gene mRNA. Br J Cancer 82:429-435.

Leemans CR, Tiwari R, Nauta JJ, Van der Waal I, and Snow GB (1993). Regional lymph node involvement and its significance in the development of distant metastases in head and neck carcinoma. Cancer 71:452-456.

Leemans CR, Tiwari R, Van der Waal I, Karim AB, Nauta JJ, and Snow GB (1990). The efficacy of comprehensive neck dissection with or without postoperative radiotherapy in nodal metastases of squamous cell carcinoma of the upper respiratory and digestive tracts. Laryngoscope 100:11941198.

Liefers GJ, Cleton-Jansen AM, Van de Velde CJ, Hermans J, Van Krieken JH, Cornelisse CJ, and Tollenaar RA (1998). Micrometastases and survival in stage II colorectal cancer. N Engl J Med 339:223-228.

McDonald LA, Walker DM, and Gibbins JR (1998). Cervical lymph node involvement in head and neck cancer detectable as expression of a spliced transcript of type II keratin K5. Oral Oncol 34:276-283.

McGuckin MA, Cummings MC, Walsh MD, Hohn BG, Bennett IC, and Wright RG (1996). Occult axillary node metastases in breast cancer: Their detection and prognostic significance. Br J Cancer 73:88-95.

Muir C and Weiland L (1995). Upper aerodigestive tract cancers. Cancer 75:147-153.

Nieuwenhuis EJC, Jaspars LH, Castelijns JA, Bakker B, Wishaupt RGA, Denkers F, Leemans CR, Snow GB, and Brakenhoff RH (2003). Quantitative molecular detection of minimal residual head and neck cancer in lymph node aspirates. Clin Cancer Res 9:755-761.

Pantel K, Cote RJ, and Fodstad R (1999). Detection and clinical importance of micrometastatic disease. J Natl Cancer Inst 91:1113-1124.

Pantel K (1996). Detection of minimal disease in patients with solid tumors. J Hematother 5:359-367.

Quak JJ, Balm AJM, van Dongen GAMS, Brakkee JGP, Scheper RJ, Snow GB, and Meijer CJLM (1990). A 22-kd surface antigen detected by monoclonal antibody $\mathrm{E} 48$ is exclusively expressed in stratified squamous and transitional epithelia. Am J Pathol 136:191-197.

Shah JP (1990). Cervical lymph node metastases: Diagnostic, therapeutic, and prognostic implications. Oncology 4:6169. 
Snow GB, Annyas AA, van Slooten EA, Bartelink $H$, and Hart AA (1982). Prognostic factors of neck node metastasis. Clin Otolaryngol 7:185-192.

Specht K, Richter T, Muller U, Walch A, Werner M, and Hofler $H$ (2001). Quantitative gene expression analysis in microdissected archival formalin-fixed and paraffin-embedded tissue. Am J Pathol 158:419-429.

Stell PM, Morton RP, and Singh SD (1983). Cervical lymph node metastases: The significance of the level of the lymph node. Clin Oncol 9:101-107.
Van den Brekel MWM, Van der Waal I, Meijer CJLM, Freeman JL, Castelijns JA, and Snow GB (1996). The incidence of micrometastases in neck dissection specimens obtained from elective neck dissections. Laryngoscope 106:987-991.

Van Houten VMM, Tabor MP, Van den Brekel MWM, Denkers F, Wishaupt RG, Kummer JA, Snow GB, and Brakenhoff RH (2000). Molecular assays for the diagnosis of minimal residual head-and-neck cancer: Methods, reliability, pitfalls, and solutions. Clin Cancer Res 6:3803-3816. 